Article

\title{
Climatic Characteristics of Reference Evapotranspiration in the Hai River Basin and Their Attribution
}

\author{
Lingling Zhao ${ }^{1,2}$, Jun Xia ${ }^{2,3, *}$, Leszek Sobkowiak ${ }^{4}$ and Zongli $\mathrm{Li}^{5}$
}

1 Guangzhou Institute of Geography, No.100 Xianliezhong Road, Guangzhou 510070, China E-Mail: linglingzhao@foxmail.com

2 Key Laboratory of Water Cycle \& Related Land Surface Processes, Institute of Geographic Sciences and Natural Resources Research, Chinese Academy of Sciences, Beijing 100101, China;

3 State Key Laboratory of Water Resources \& Hydropower Engineering Science, Wuhan University Wuhan 430072, China

4 Institute of Physical Geography and Environmental Planning, Adam Mickiewicz University, Poznan 61-680, Poland; E-Mail: lesob@amu.edu.pl

5 General Institute of Water Resources and Hydropower Planning and Design, Ministry of Water Resources of China, Beijing 100120, China. E-Mail: lizongli@igsnrr.ac.cn

* Author to whom correspondence should be addressed; E-Mail: xiaj@igsnrr.ac.cn; Tel.: +86-020-876-855-13-809; Fax: +86-020-876-855-13-809.

Received: 26 February 2014; in revised form: 16 May 2014 / Accepted: 20 May 2014 / Published: 28 May 2014

Abstract: Based on the meteorological data from 46 stations in the Hai River Basin (HRB) from 1961-2010, the annual and seasonal variation of reference evapotranspiration was analyzed. The sensitivity coefficients combined with the detrend method were used to discuss the dominant factor affecting the reference evapotranspiration $\left(\mathrm{ET}_{\mathrm{o}}\right)$. The obtained results indicate that the annual reference evapotranspiration is dominated by the decreasing trends at the confidence level of $95 \%$ in the southern and eastern parts of the HRB. The sensitivity order of climatic variables to $\mathrm{ET}_{\mathrm{o}}$ from strong to weak is: relativity humidity, temperature, shortwave radiation and wind speed, respectively. However, comprehensively considering the sensitivity and its variation strength, the detrend analysis indicates that the decreasing trends of $\mathrm{ET}_{\mathrm{o}}$ in eastern and southern $\mathrm{HRB}$ may be caused mainly by the decreasing wind speed and shortwave radiation. As for the relationship between human activity and the trend of $\mathrm{ET}_{\mathrm{o}}$, we found that $\mathrm{ET}_{\mathrm{o}}$ decreased more significantly on the plains than in the mountains. By contrast, the population density increased more considerably from 2000 to 2010 on the plains than in the mountains. Therefore, in this paper, the 
correlation of the spatial variation pattern between $\mathrm{ET}_{\mathrm{o}}$ and population was further analyzed. The spatial correlation coefficient between population and the trend of $\mathrm{ET}_{\mathrm{o}}$ is -0.132 , while the spatial correlation coefficient between the trend of $\mathrm{ET}_{\mathrm{o}}$ and elevation, temperature, shortwave radiation and wind speed is $0.667,0.668,0.749$ and 0.416 , respectively. This suggests that human activity has a certain influence on the spatial variation of $\mathrm{ET}_{\mathrm{o}}$, while natural factors play a decisive role in the spatial variation of reference evapotranspiration in this area.

Keywords: climatic variation; reference evapotranspiration; Penman-Monteith method; Hai River Basin

\section{Introduction}

Hydrologists have found that climate change has resulted in some changes in the water cycle [1-3]. One major challenge of recent hydrological modeling activities is the assessment of the effects of climate change on the terrestrial water cycle [4]. Hydrological models are usually based on the calculation of reference evapotranspiration and reducing it to the actual evapotranspiration by considering the soil moisture status [5] or the number of days since the last rainfall event [6]. Therefore, analyzing how climate change affects reference evapotranspiration $\left(\mathrm{ET}_{\mathrm{o}}\right)$ is critical for understanding the impact of climate change on the hydrological cycle. According to Allen et al. [7], $\mathrm{ET}_{\mathrm{o}}$ is the evapotranspiration from the reference surface, which is a hypothetical grass reference crop with an assumed crop height of $0.12 \mathrm{~m}$, a fixed surface resistance of $70 \mathrm{~s} \mathrm{~m}^{-1}$ and an albedo of 0.23 .

The Hai River Basin (HRB) is one of seven largest river basins and also one of the most developed areas in China, with the population accounting for about $10 \%$ of the nation's total. The middle and lower reaches of the basin are important wheat production regions in China. This region has a semi-humid and semi-arid climate and has been strongly influenced by human activities. The annual precipitation is $539 \mathrm{~mm}$, while the annual pan evaporation is $1100 \mathrm{~mm}$, making the basin vulnerable to climatic variations [7]. In recent decades, several eco-environmental problems in that area have come to the fore under the combined impacts of climate change and intensified human activities. Water resources in the HRB are currently used for irrigation, aquaculture and industries. Due to the very limited available water resources in the basin, water has been diverted from other basins to supply it for agriculture and to maintain essential ecosystem functions [8].

In order to understand how climatic variables affect $\mathrm{ET}_{\mathrm{o}}$, some studies have been carried out to evaluate evapotranspiration in the context of climate change. Zheng et al. [9] analyzed the cause of the decreased pan evaporation during 1957-2001 in the HRB, and found the reason to be the declining wind speed. Xu et al. [10] proved that the decreasing wind speed and net radiation were responsible for the $\mathrm{ET}_{\mathrm{o}}$ changes in the Changjiang River Basin of China. Liu [11], who analyzed the pan evaporation from 1955 to 2000 in China, found that the decrease in solar radiance was most likely the driving force of the reduced pan evaporation in China. Furthermore, sensitivity analysis has also been performed on the impacts of climate change [12-18]. However, the temporal pattern of $\mathrm{ET}_{\mathrm{o}}$ is not only influenced by the sensitivity of climatic variables, but also by their variation patterns. 
The spatial pattern of $\mathrm{ET}_{\mathrm{o}}$ in $\mathrm{HRB}$ has not been addressed in the literature, yet. In this study, we calculated $\mathrm{ET}_{\mathrm{o}}$ using the FAO-56 Penman-Monteith equation and analyzed the temporal-spatial pattern in $\mathrm{ET}_{\mathrm{o}}$ and its driving variables. Attribution analysis was then performed to quantify the contribution of each input variable to $\mathrm{ET}_{\mathrm{o}}$ variation. The objective of this paper is to exhibit the temporal-spatial variation pattern of $\mathrm{ET}_{\mathrm{o}}$ over the past 50 years in the $\mathrm{HRB}$, then to detect the reason for these characteristics and to quantify the contribution of the climatic variation to $\mathrm{ET}_{\mathrm{o}}$.

\section{Study Area and Data}

The Hai River Basin is located in north China and is one of seven largest river basins in the country. The basin is bounded in the north by Mount Tangshan, in the west by Mount Taihang and in the east by the Bohai Sea. Land surface elevation in the mountainous north and west of the study area is generally above $2000 \mathrm{~m}$ a.s.l. On the floodplains, however, surface elevation hardly exceeds $100 \mathrm{~m}$ a.s.1. The basin occupies an area of $3.2 \times 10^{5} \mathrm{~km}^{2}\left(34.9-42.8^{\circ} \mathrm{N}, 112.0-119.8^{\circ} \mathrm{E}\right)$ and includes five provinces and the two megacities of Beijing and Tianjin (Figure 1). Climatically, the HRB belongs to the East Asian monsoon region. The annual mean temperature varies from $8{ }^{\circ} \mathrm{C}$ to $12{ }^{\circ} \mathrm{C}$, while annual precipitation is about $539 \mathrm{~mm}$; relative humidity varies from $50 \%$ to $70 \%$.

Figure 1. The location of the Hai River Basin (HRB).

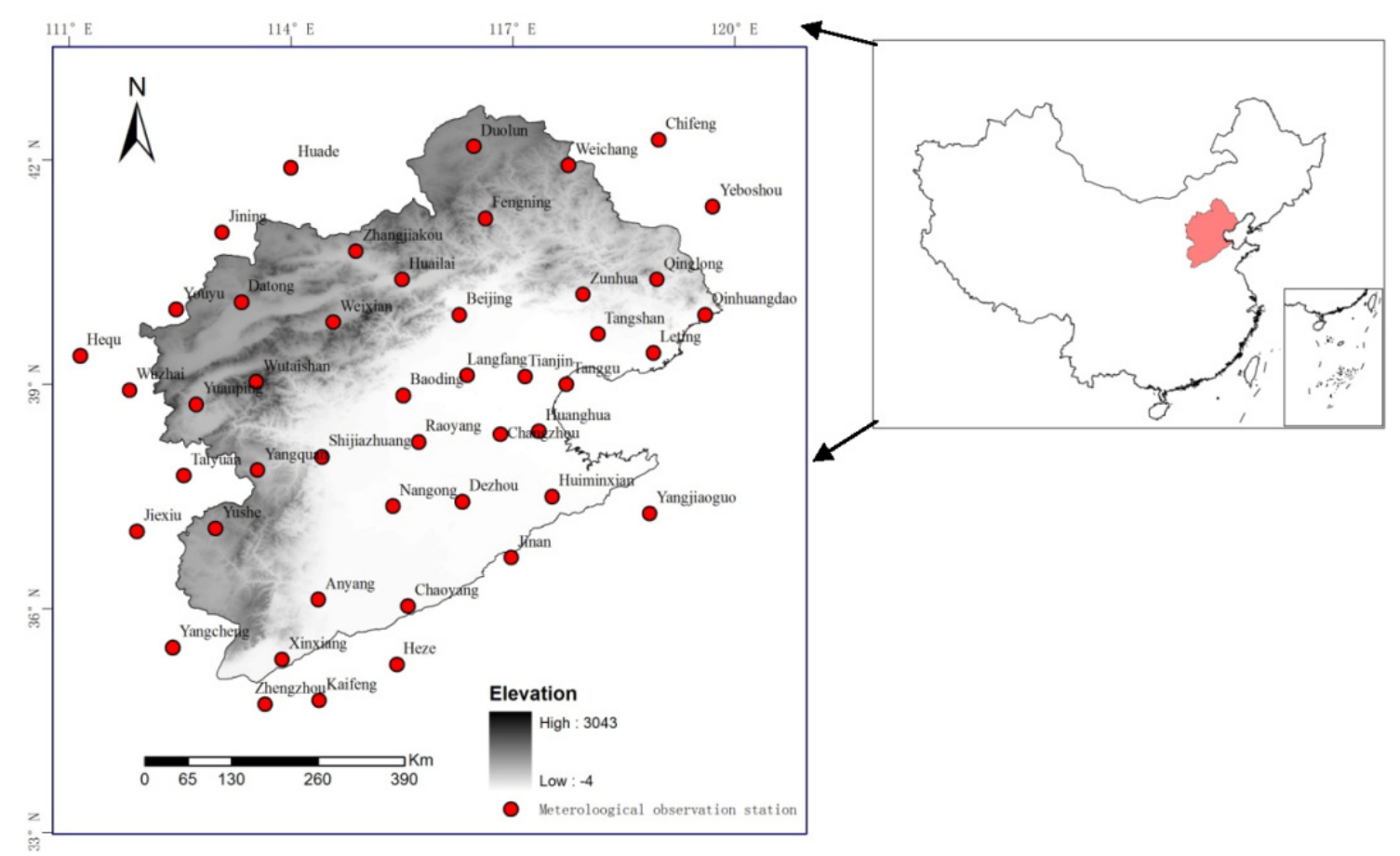

Data from 46 National Meteorological Observatory stations included daily observations of the maximum, minimum and mean air temperatures $\left(T_{\max }, T_{\min }, T_{a}\right)$, wind speed $(U)$, relative humidity $(R h)$ and sunshine duration $(n)$ for the period from 1960 to 2010 and pan evaporation ( $\mathrm{E}_{\mathrm{pan}}$ ) for 1960-2001. $\mathrm{E}_{\text {pan }}$ was measured using a metal pan, $20 \mathrm{~cm}$ in diameter and $10 \mathrm{~cm}$ high, installed $70 \mathrm{~cm}$ above the ground. The data have been provided by the National Climatic Center of China Meteorological Administration. The locations of the stations are shown in Figure 1, while the details of the stations are 
listed in Table 1. In Table 1, the annual $\mathrm{ET}_{\mathrm{o}}$ is the average value from 1960 to 2010 calculated using the FAO-56 Penman-Monteith method.

Table 1. Basic data on the investigated stations in HRB.

\begin{tabular}{|c|c|c|c|c|c|c|c|c|c|}
\hline Name & No. & $\begin{array}{c}\text { Longitude } \\
\left({ }^{\circ}\right) \\
\end{array}$ & $\begin{array}{c}\text { Latitude } \\
\left(^{\circ}\right) \\
\end{array}$ & $\begin{array}{c}\text { Elevation } \\
\text { (m) }\end{array}$ & Name & No. & $\begin{array}{c}\text { Longitude } \\
\left(^{\circ}\right) \\
\end{array}$ & $\begin{array}{c}\text { Latitude } \\
\left({ }^{\circ}\right) \\
\end{array}$ & $\begin{array}{c}\text { Elevation } \\
\text { (m) }\end{array}$ \\
\hline Wutaishan & 53588 & 113.53 & 39.03 & 2896 & Changzhou & 54616 & 116.83 & 38.33 & 10 \\
\hline Weixian & 53593 & 114.57 & 39.83 & 910 & Tanggu & 54623 & 117.72 & 39.00 & 3 \\
\hline Yuanping & 53673 & 112.72 & 38.73 & 828 & Huanghua & 54624 & 117.35 & 38.37 & 7 \\
\hline Shijiazhuang & 53698 & 114.42 & 38.03 & 81 & Nangong & 54705 & 115.38 & 37.37 & 27 \\
\hline Yangquan & 53782 & 113.55 & 37.85 & 742 & Dezhou & 54714 & 116.32 & 37.43 & 21 \\
\hline Yushe & 53787 & 112.98 & 37.07 & 1041 & Huiminxian & 54725 & 117.53 & 37.50 & 12 \\
\hline Anyang & 53898 & 114.37 & 36.12 & 76 & Chaoyang & 54808 & 115.58 & 36.03 & 43 \\
\hline Xinxiang & 53986 & 113.88 & 35.32 & 73 & Huade & 53391 & 114.00 & 41.90 & 1483 \\
\hline Duolun & 54208 & 116.47 & 42.18 & 1245 & Shiyu & 53478 & 112.45 & 40.00 & 1346 \\
\hline Fengning & 54308 & 116.63 & 41.22 & 660 & Jiying & 53480 & 113.07 & 41.03 & 1419 \\
\hline Weichang & 54311 & 117.75 & 41.93 & 843 & Hequ & 53564 & 111.15 & 39.38 & 862 \\
\hline Zhuangjiakou & 54401 & 114.88 & 40.78 & 724 & Wuzhai & 53663 & 111.82 & 38.92 & 1401 \\
\hline Huailai & 54405 & 115.50 & 40.40 & 537 & Taiyuan & 53772 & 112.55 & 37.78 & 778 \\
\hline Zunhua & 54429 & 117.95 & 40.20 & 55 & Jiexiu & 53863 & 111.92 & 37.03 & 744 \\
\hline Qinglong & 54436 & 118.95 & 40.40 & 227 & Yangcheng & 53975 & 112.40 & 35.48 & 660 \\
\hline Qinhuangdao & 54449 & 119.60 & 39.93 & 2 & Chifeng & 54218 & 118.97 & 42.27 & 568 \\
\hline Beijing & 54511 & 116.28 & 39.93 & 54 & Yeboshou & 54326 & 119.70 & 41.38 & 662 \\
\hline Langfang & 54518 & 116.38 & 39.12 & 9 & Yangjiaogou & 54736 & 118.85 & 37.27 & 6 \\
\hline Tianjin & 54527 & 117.17 & 39.10 & 3 & Jinan & 54823 & 116.98 & 36.68 & 52 \\
\hline Tangshan & 54534 & 118.15 & 39.67 & 28 & Heze & 54906 & 115.43 & 35.25 & 50 \\
\hline Leting & 54539 & 118.90 & 39.42 & 11 & Zhengzhou & 57083 & 113.65 & 34.72 & 110 \\
\hline Baoding & 54602 & 115.52 & 38.85 & 17 & Kaifeng & 57091 & 114.38 & 34.77 & 73 \\
\hline Raoyang & 54606 & 115.73 & 38.23 & 19 & Datong & 53487 & 113.33 & 40.10 & 1067 \\
\hline
\end{tabular}

\section{Methodologies}

\subsection{Penman-Monteith Method}

The Penman-Monteith method recommended by FAO (Food and Agriculture Organization) [19] as the standard method for determining reference evapotranspiration was used in this study. The method was selected because it is physically based and explicitly incorporates both physiological and aerodynamic parameters.

$$
\mathrm{ETo}=\frac{0.408 \Delta\left(\mathrm{R}_{\mathrm{n}}-\mathrm{G}\right)+\gamma \frac{900}{(\mathrm{~T}+273)} \mathrm{U}_{2}\left(\mathrm{e}_{\mathrm{s}}-\mathrm{e}_{\mathrm{a}}\right)}{\Delta+\gamma\left(1+0.34 \mathrm{U}_{2}\right)}
$$

where, $E_{\mathrm{o}}$ is the reference evapotranspiration $\left(\mathrm{mm} /\right.$ day); $\mathrm{R}_{\mathrm{n}}$ is net radiation at the crop surface $\left(\mathrm{MJ} / \mathrm{m}^{2} /\right.$ day); $\mathrm{G}$ is soil heat flux density $\left(\mathrm{MJ} / \mathrm{m}^{2} /\right.$ day); $\mathrm{T}$ is mean daily air temperature $\left({ }^{\circ} \mathrm{C}\right), \mathrm{U}_{2}$ is wind speed at $2 \mathrm{~m}$ height $(\mathrm{m} / \mathrm{s}) ; e_{s}$ is saturation vapor pressure $(\mathrm{kPa}) ;\left(\mathrm{e}_{\mathrm{s}}-\mathrm{e}_{\mathrm{a}}\right)$ is the saturation vapor pressure deficit $(\mathrm{kPa}) ; \Delta$ is the slope of vapor pressure $\left(\mathrm{kPa} /{ }^{\circ} \mathrm{C}\right)$ and $\gamma$ is the psychometric constant $\left(\mathrm{kPa} /{ }^{\circ} \mathrm{C}\right)$. 
The computation of all data required for the calculation and relevant procedures are given in Chapter 3 of the FAO Paper 56 [19].

\subsection{Trend Detection and Sensitivity Analysis Method}

The rank-based nonparametric Mann-Kendall statistical test [20,21] is commonly used for trend detection, because of its robustness for non-normally distributed and censored data, which are frequently encountered in hydroclimatic time series. In this method, the test statistic, $Z$, is as follows:

$$
\begin{gathered}
Z=S / \sigma_{s}^{2} \\
\sigma_{s}^{2}=\frac{n(n-1)(2 n+5)-\sum_{i-1}^{n} e_{i} i(i-1)(2 i+5)}{18} \sum_{i=1}^{n-1} \sum_{j=i+1}^{n} \operatorname{sgn}\left(x_{j}-x_{i}\right) \\
\operatorname{sgn}(x)= \begin{cases}1 & \text { if } \mathrm{x}>0 \\
0 & \text { if } \mathrm{x}=0 \\
-1 & \text { if } \mathrm{x}<0\end{cases}
\end{gathered}
$$

Equation (2) gives the standard deviation of $S$ with correction for ties in the data, with $e_{i}$ denoting the number of ties of extent $i$. The upward or downward trend in the data is statistically significant if $|Z|>\mu_{1-\alpha / 2}$, where $\mu_{1-\alpha / 2}$ is the $(1-\alpha / 2)$ quantity of the standard normal distribution and when $\alpha=0.05, u_{1-\alpha / 2}=1.96$. Positive $Z$ indicates an increasing trend in the time series, while negative $Z$, a decreasing one.

Original measurements of air temperature $\left(T_{a}\right)$, wind speed $(U)$ and relative humidity $(R h)$ were chosen for the sensitivity analyses. The fourth applied variable is shortwave radiation $\left(R_{s}\right)$. This is because shortwave radiation is one of the input variables in a number of semi-physical and semi-empirical equations that are used to derive the net energy flux required by the Penman method [22]. Following the procedure described by Allen [19], $R_{s}$ can be estimated with the following formula that relates surface shortwave radiation to extraterrestrial radiation and daily sunshine duration:

$$
\mathrm{R}_{\mathrm{s}}=\left(\mathrm{a}_{\mathrm{s}}+\mathrm{b}_{\mathrm{s}} \frac{\mathrm{n}}{\mathrm{N}}\right) \mathrm{R}_{\mathrm{a}}
$$

where $R_{S}$ is shortwave radiation, $n$ is daily sunshine duration (h); $N$ is maximum possible duration of sunshine or daylight hours $(\mathrm{h}) ; n / N$ is relative sunshine duration; $R_{a}$ is extraterrestrial radiation and $\mathrm{a}_{\mathrm{s}}$ and $b_{\mathrm{s}}$ are the regression constants. The recommended values $a_{s}=0.25$ and $b_{s}=0.75$ were used in this study.

In multivariate models, different variables have different dimensions and different ranges of values, which make it difficult to compare the sensitivity by partial derivatives. Consequently, the partial derivative is transformed into a non-dimensional form: 


$$
\mathrm{Sx}=\lim _{\Delta x / \mathrm{x}}\left(\frac{\frac{\Delta \mathrm{ETo}}{\mathrm{ETo}}}{\frac{\Delta \mathrm{x}}{\mathrm{x}}}\right)=\frac{\partial \mathrm{ETo}}{\partial \mathrm{x}} \cdot \frac{\mathrm{x}}{\mathrm{ETo}}
$$

Basically, a positive/negative sensitivity coefficient of a variable indicates that $\mathrm{ET}_{\mathrm{o}}$ increases/decreases as the variable increases; the larger the sensitivity coefficient, the larger the effect a given variable has on $\mathrm{ET}_{\mathrm{o}}$.

\subsection{Spatial Correlation Coefficient}

Correlation coefficients depict the spatial relationship between two datasets. The correlation between two variables is a measure of dependency between these variables. It is the ratio of the covariance between the two datasets divided by the product of their standard deviations. Because it is a ratio, it is a unit-less number. The equation to calculate the correlation is [23]:

$$
\operatorname{Corr}_{i j}=\frac{\operatorname{Cov}_{i j}}{\delta_{i} \delta_{j}}
$$

where, $\operatorname{Cov}_{i j}$ is the covariance; $\delta_{i}, \delta_{j}$ are the standard deviations of dataset $i$ and $j$, respectively.

The calculated covariance matrix in this paper contains values of variances and covariances. The variance is a statistical measure showing how much variance there is from the mean. The remaining entries within the covariance matrix are the covariances between all pairs of the input datasets. The following formula is used to determine the covariance between datasets $i$ and $j$ :

$$
\operatorname{Cov}_{i j}=\frac{\sum_{k=1}^{N}\left(Z_{i k}-\mu_{i}\right)\left(Z_{j k}-\mu_{j}\right)}{N-1}
$$

where, $Z_{i k}, Z_{j k}$ are the values of dataset $i$ and dataset $j$, respectively in location $k ; \mu_{i}, \mu_{j}$ are the average values of datasets $i$ and $j$, respectively; $i, j$ is the order of dataset; $N$ is the number of dataset; $K$ denotes a particular location.

Correlation ranges from +1 to -1 . A positive correlation indicates a direct relationship between two datasets, such as when the cell values of one datasets increase, the cell values of another datasets are also likely to increase. A negative correlation means that one variable changes inversely to the other. A correlation of zero means that two datasets are independent of one another.

\subsection{Detrend Method}

The variation pattern of ETo is determined by multi-climatic variables, including their sensitivity to ETo and variation fluctuations. The detrend method is a combination method that considers both the sensitivity coefficient and the fluctuation of the climatic variables.

The detrend method is a way of quantifying the contribution of climatic variables to the annual variation of $\mathrm{ET}_{\mathrm{o}}$. This method shows the contribution in graphs and vividly describes how the climatic variables influence $\mathrm{ET}_{\mathrm{o}}$. In this study, the following steps were performed: (1) use of the simple linear regression method to detect the changing slope of the main climatic variables; (2) detection of the significance of the slope by the $t$-test; (3) removal of the significant slope of main climatic variables to 
make them stationary time series; (4) recalculation of reference evapotranspiration using each time the original series of three variables and the detrend data of one variable; (5) comparison of the results with the original reference evapotranspiration; the observed difference is considered as the influence of those variables on the trend [22].

\section{Results and Discussion}

\subsection{Correlation between $E T_{o}$ and $E_{\text {pan }}$}

Figure 2 shows the monthly correlation coefficients $\left(\mathrm{R}^{2}\right)$ between $\mathrm{ET}_{\mathrm{o}}$ and $\mathrm{E}_{\mathrm{pan}}$ in $\mathrm{HRB}$. As can be seen, the lowest correlation coefficient is 0.93 , while the highest is 0.97 . Spatially, mountain areas in the northwest and coastal areas in the southeast have higher correlation coefficients than plains in the central part of the study area. Mountain and coastal areas are more humid than plains, which is consistent with the research conclusion of Brutsaert [24] that in humid areas, reference evaporation has a better relationship with pan evaporation.

Figure 2. Correlation between $\mathrm{ET}_{\mathrm{o}}$ and $\mathrm{E}_{\mathrm{pan}}$ in the $\mathrm{HRB}$.

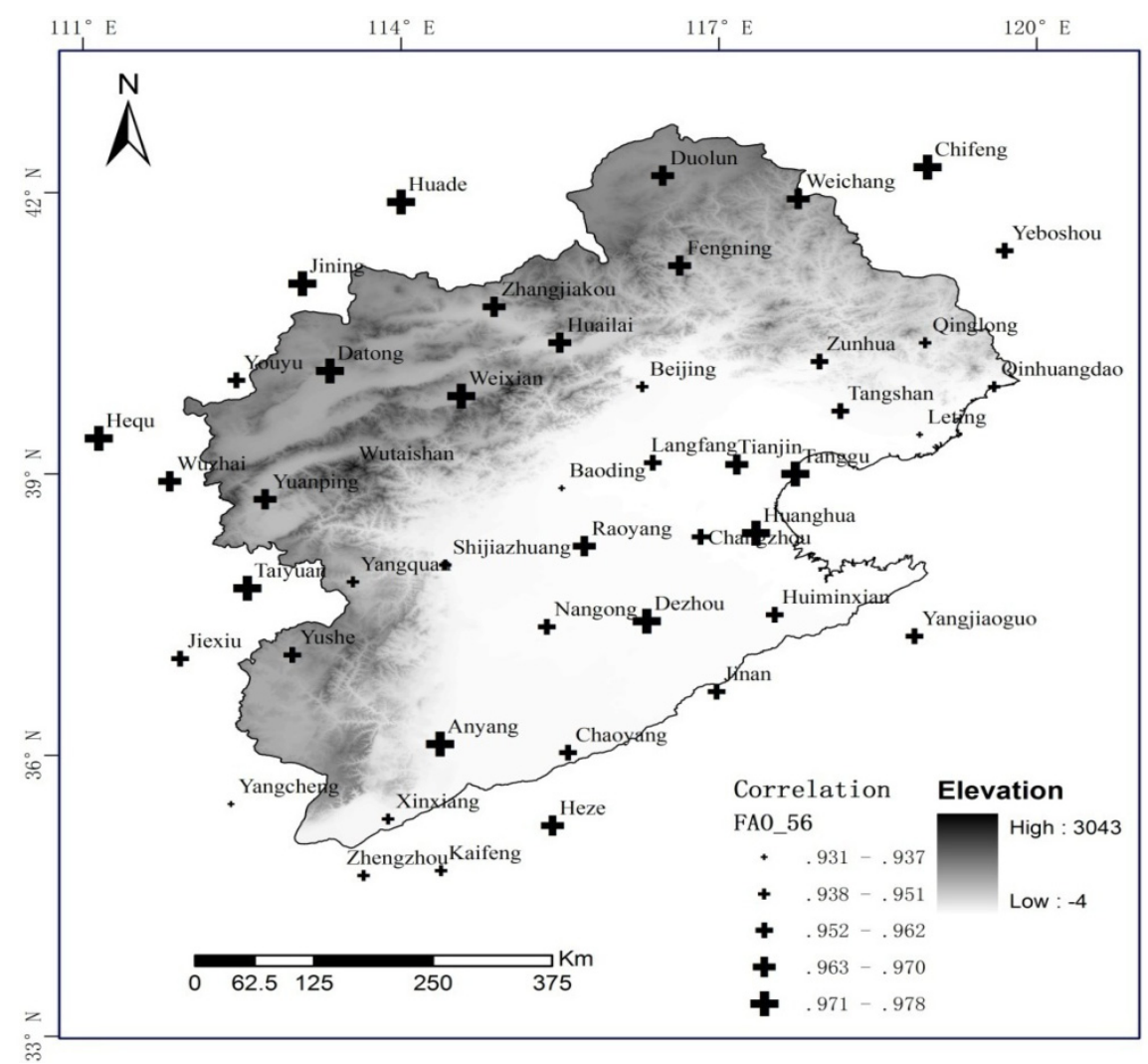

\subsection{Spatial-Temporal Variation of $E T_{o}$ in $H R B$}

To study the spatial distribution of the trend of $\mathrm{ET}_{\mathrm{o}}$ from 1960 to 2010 in the HRB, the Mann-Kendall test was used for each station to establish the $\mathrm{ET}_{\mathrm{o}}$ trends. The trends of annual and seasonal $\mathrm{ET}_{\mathrm{o}}$ were tested at the $95 \%$ confidence level. Decreasing trends in annual $\mathrm{ET}_{\mathrm{o}}$ were observed at 28 stations located mostly on the eastern and southern plains of the HRB. However, increasing trends in the 
annual $\mathrm{ET}_{\mathrm{o}}$ were observed at three sites (Datong, Wutaishan, Weixian) located in the western mountain region of the HRB (Figure 3 ).

Figure 3. The annual trend of $\mathrm{ET}_{\mathrm{o}}$ in the HRB.

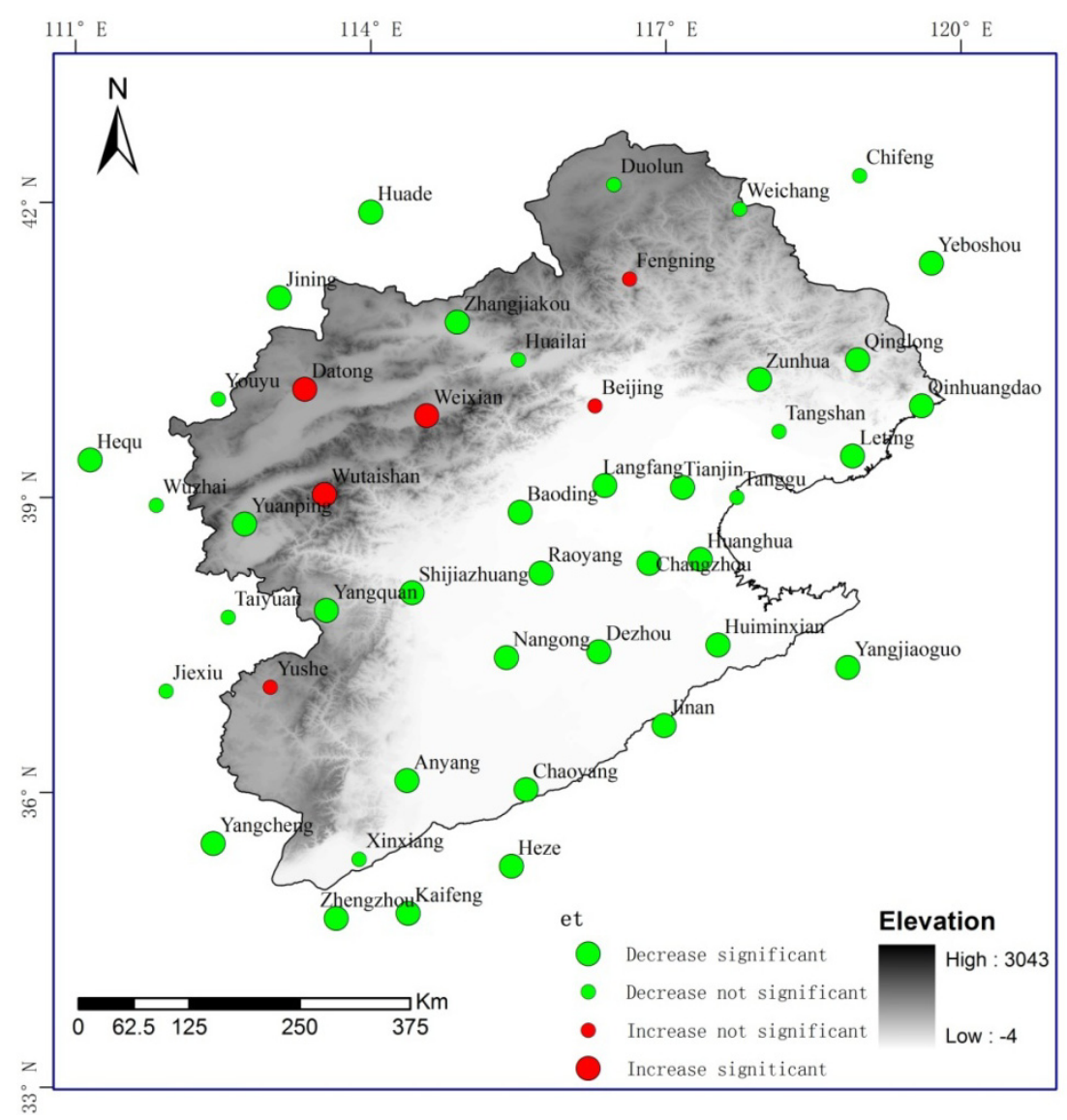

As for the variation pattern of seasonal $\mathrm{ET}_{0}$, Figure 4 shows large differences in the spatial distribution of trends in seasonal $\mathrm{ET}_{\mathrm{o}}$ in the $\mathrm{HRB}$. As can be seen, stations with decreasing trends in spring are mainly distributed in the southeastern plain region of the study area. The significantly increasing trend of $\mathrm{ET}_{\mathrm{o}}$ was found only at Wutaishan station in the western mountain region of the HRB. Twenty-nine stations characterized by decreasing trends of $\mathrm{ET}_{\mathrm{o}}$ in summer are concentrated mainly in the eastern and southern regions of the HRB. Only one station is dominated by the increasing trend of $\mathrm{ET}_{\mathrm{o}}$ in summer. In autumn, only nine out of 46 stations show a trend in $\mathrm{ET}_{\mathrm{o}}$. Among them, eight stations present decreasing trends, while one station shows an increasing trend. The changing trend patterns in winter are similar to those in autumn: 16 out of 46 stations are dominated by the decreasing winter $\mathrm{ET}_{\mathrm{o}}$, while two stations in the western plateau region display the increasing trend.

\subsection{Variation Pattern of Climatic Variables}

Shortwave radiation decreases in the whole basin, and most trends are significant at the 0.05 significance level (Figure 5). The maximum and minimum temperatures increased in the whole HRB (Figure 5). The maximum temperatures in the southern mountain area increase more significantly than on the northern plains; the average $p$-value of the Mann-Kendall test for the whole basin is 2.9 
(Table 2). The minimum temperatures increase more obviously than the maximum ones; the average $p$-value of the Mann-Kendall test for the whole basin is five. Relative humidity decreases in most of the basin, and this trend is significant in most sites of the mountain areas. As to the wind speed, the decreasing trends are significant in most parts of the basin at the 0.05 significance level.

Figure 4. The seasonal trend of $\mathrm{ET}_{\mathrm{o}}$ in the HRB. (a) Spring; (b) Summer; (c) Winter; (d) Autumn.

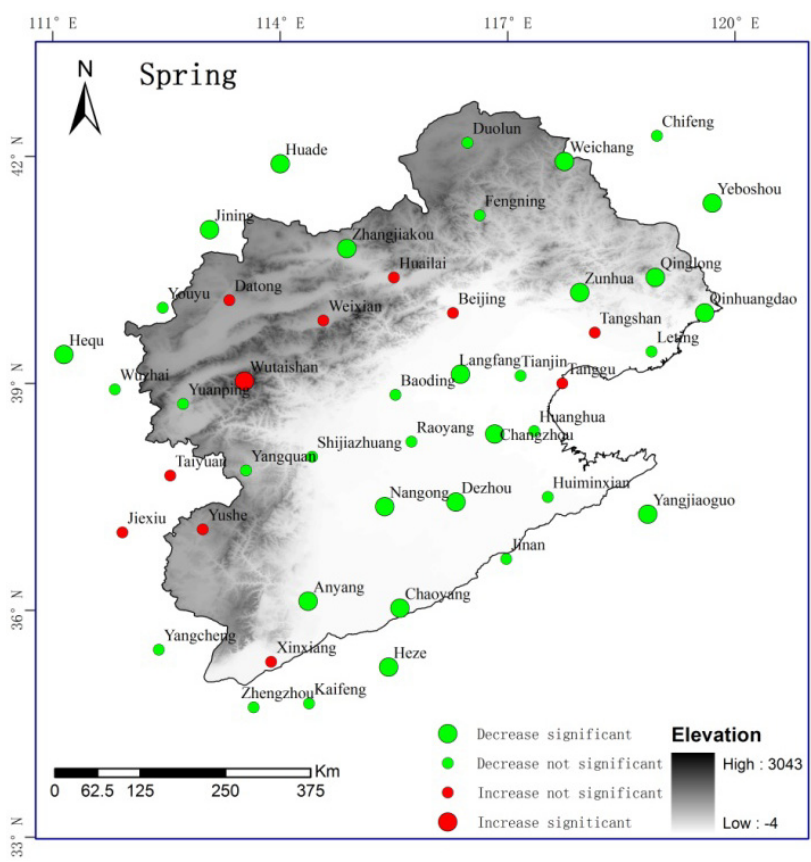

(a)

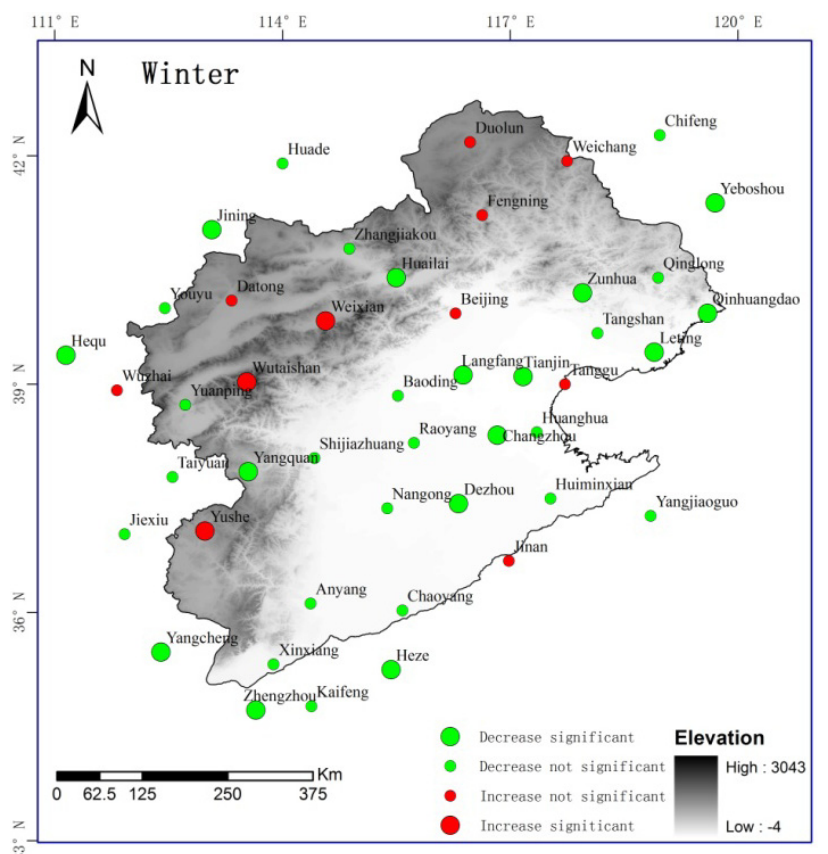

(c)

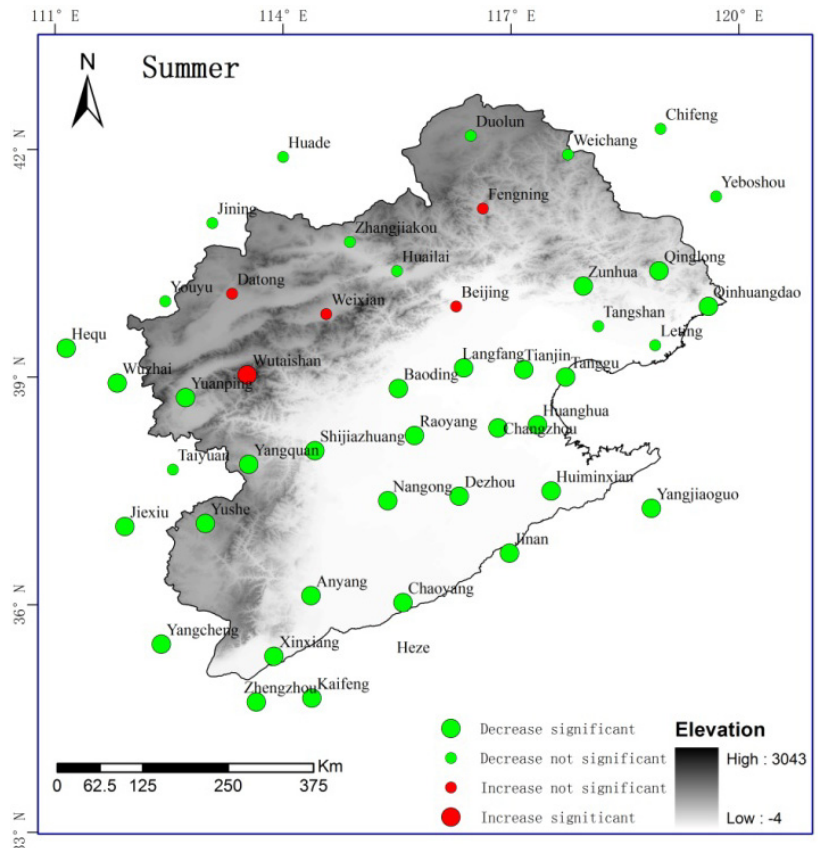

(b)

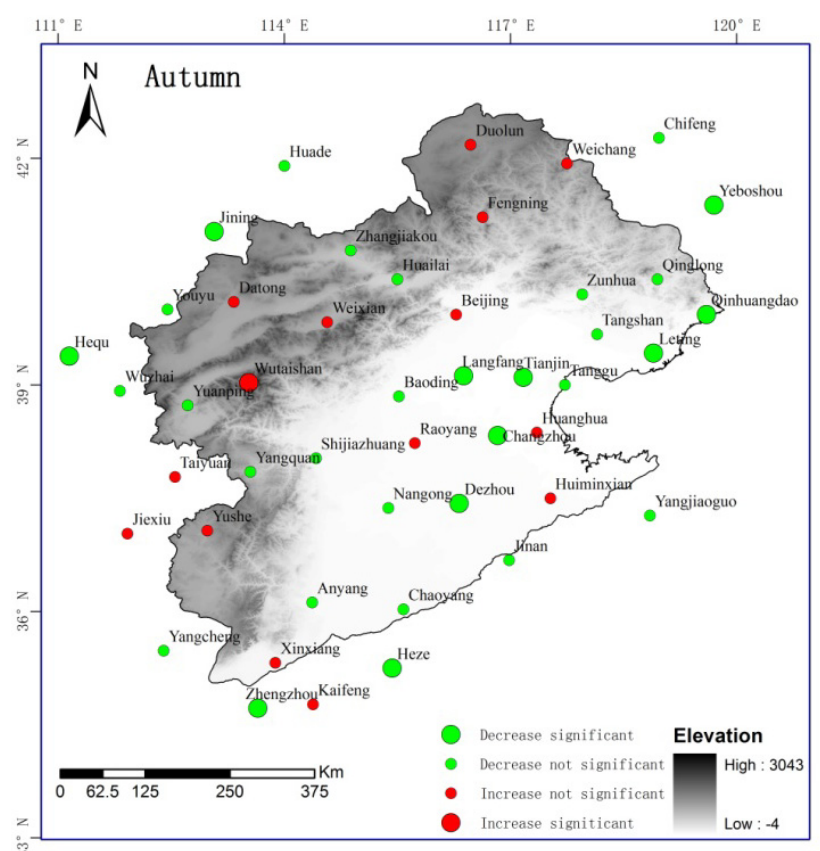

(d) 
Figure 5. The trend of main climatic variables in the HRB. (a) The trend of $T_{a}$; (b) The trend of $\mathrm{R}_{\mathrm{s}}$; (c) The trend of $\mathrm{U}$; (d) The trend of $\mathrm{Rh}$.

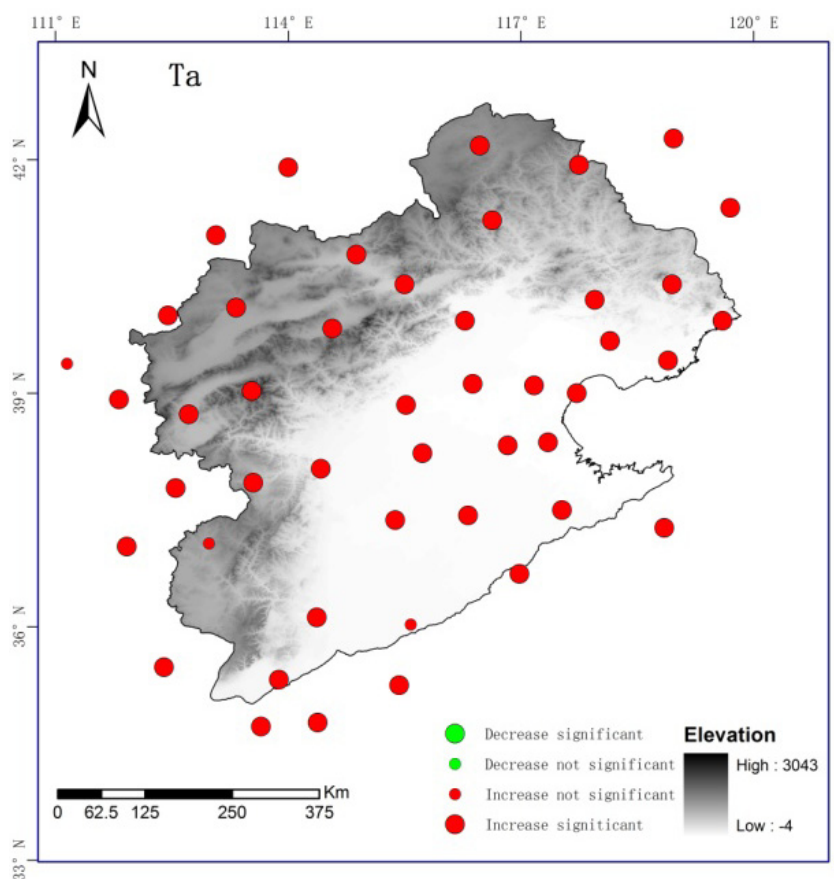

(a)

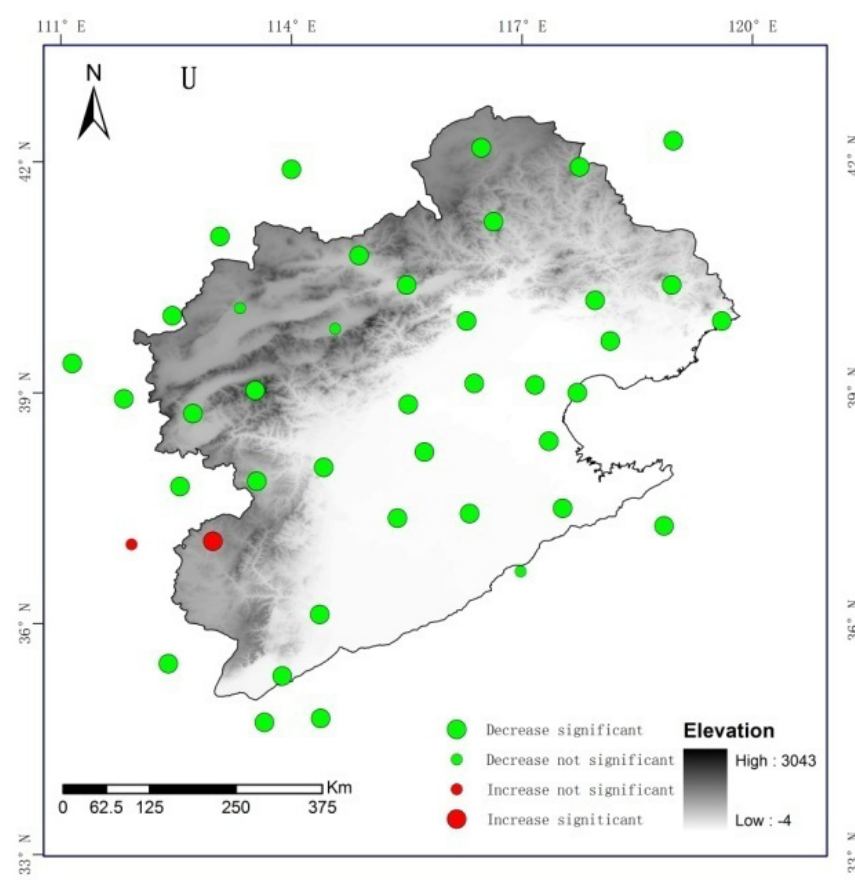

(c)

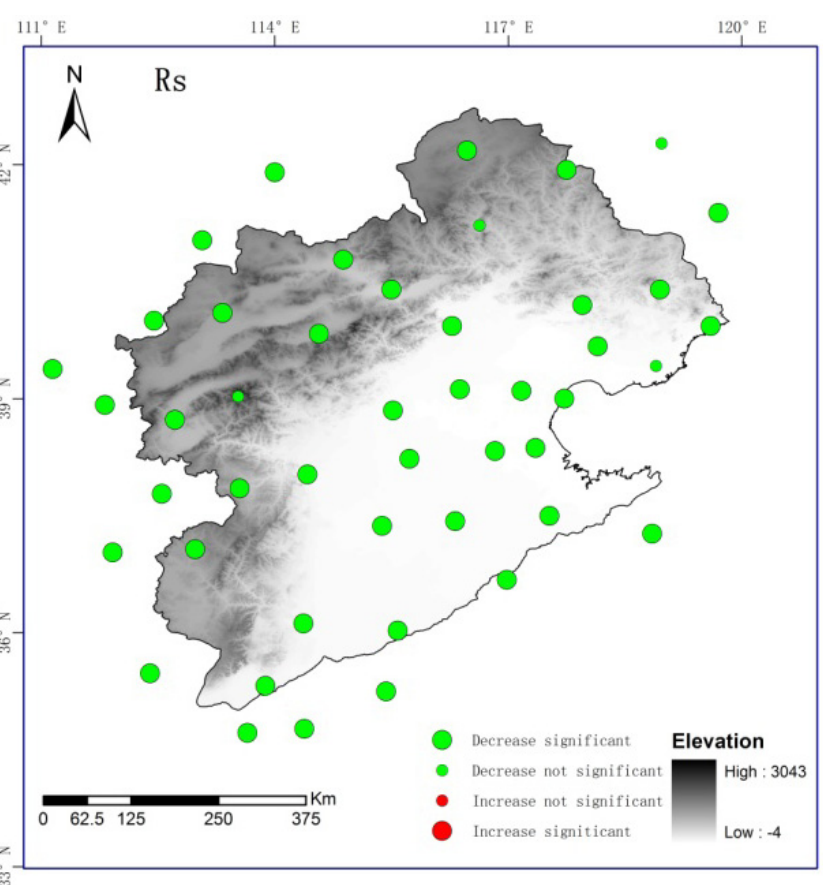

(b)

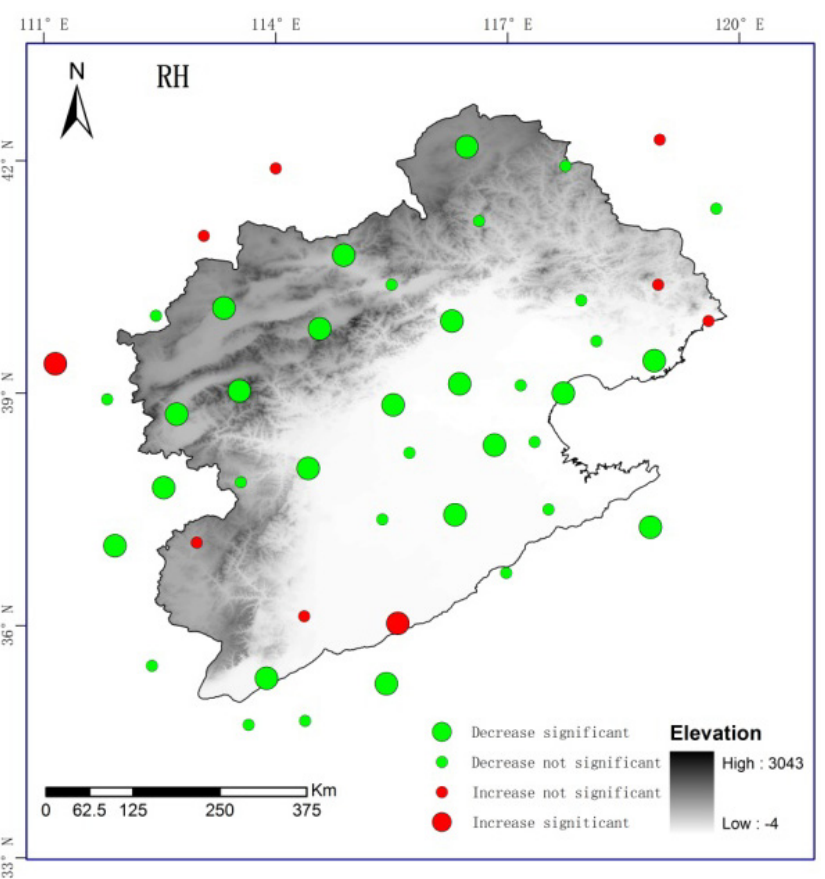

(d)

Table 2. The Mann-Kendall test value of the main climate variables at the three stations.

\begin{tabular}{ccccc}
\hline Station name & $\boldsymbol{T}_{\boldsymbol{a}}$ & $\boldsymbol{U}$ & $\boldsymbol{R} \boldsymbol{h}$ & $\boldsymbol{R}_{\boldsymbol{s}}$ \\
\hline Datong & 4.78 & -1.55 & -1.81 & -2.54 \\
Wutaishan & 4.30 & -5.21 & -3.57 & -0.54 \\
Weixian & 4.87 & -0.92 & -3.07 & -2.04 \\
Mean value of the HRB & 4.16 & -4.12 & -1.41 & -3.94 \\
\hline
\end{tabular}


The increasing temperature and decreasing relative humidity will make $\mathrm{ET}_{\mathrm{o}}$ increase, while the decreasing short wave radiation and wind speed will make $\mathrm{ET}_{\mathrm{o}}$ decrease. Therefore, the decreasing trends of $\mathrm{ET}_{\mathrm{o}}$ in the HRB suggest that the increasing temperature and decreasing relative humidity slightly discount the decreasing trend, but do not change its direction; the decreasing shortwave radiation and wind speed commonly result in the decreasing $\mathrm{ET}_{\mathrm{o}}$ in the southeastern coastal area of the HRB.

In order to detect the reasons for the increasing trend of $\mathrm{ET}_{\mathrm{o}}$ in Datong, Wutaishan and Weixian stations, this paper analyzed the climate variables at these three locations. We found a Mann-Kendall test value of temperature as large as at the other investigated stations. However, relative humidity decreased faster, while shortwave radiation and wind speed (except Wutaishan) were slower compared to the mean value calculated for the whole HRB. Therefore, it can be concluded that the increasing temperature, decreasing faster relative humidity and decreasing slower shortwave radiation and wind speed result in the increasing trend of $\mathrm{ET}_{\mathrm{o}}$ at these three stations.

\subsection{Sensitivity of Climatic Variables}

Since $\mathrm{ET}_{\mathrm{o}}$ is an important indicator of climatic changes, the sensitivity coefficient was used in this study to analyze how climatic variables affect $\mathrm{ET}_{\mathrm{o}}$. The non-dimensional form of the sensitivity coefficient was employed to estimate the sensitivity of climatic variables in the HRB. Figure 6 gives the annual sensitivity coefficient of four climatic variables $\left(T_{a}, R h, R_{s}\right.$ and $\left.U\right)$ to $\mathrm{ET}_{\mathrm{o}}$ from 1960 to 2010 estimated by the FAO-56 Penman-Monteith method. Figure 6 suggests that temperature, wind speed and short wave radiation are less sensitive in the mountain areas than on the coastal plains, while relative humidity is less sensitive in the area closest to the coast than on the plains and in the mountains.

Figure 6. The sensitivity coefficients of climatic variables in the HRB. (a) The sensitivity coefficients of $\mathrm{T}_{\mathrm{a}}$; (b) The sensitivity coefficients of $\mathrm{Rh}$; (c) The sensitivity coefficients of $\mathrm{U}$;

(d) The sensitivity coefficients of $\mathrm{R}_{\mathrm{s}}$.

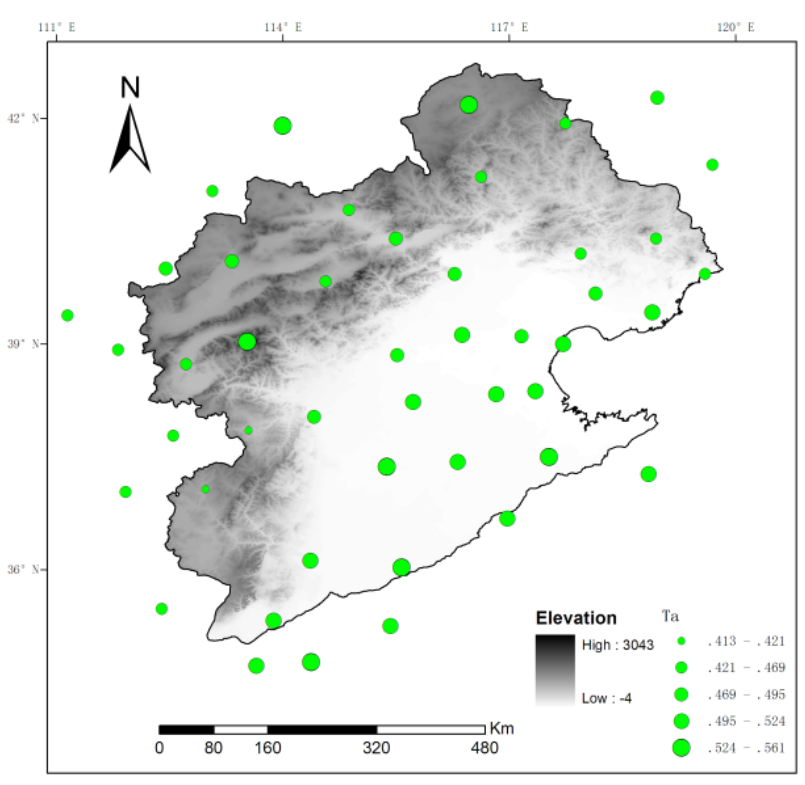

(a)

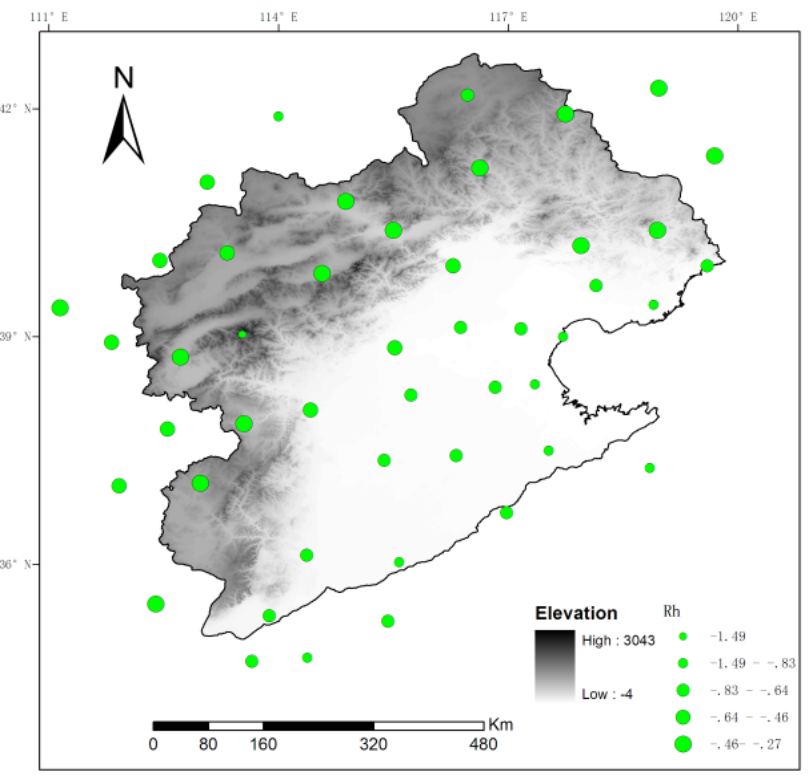

(b) 
Figure 6. Cont.

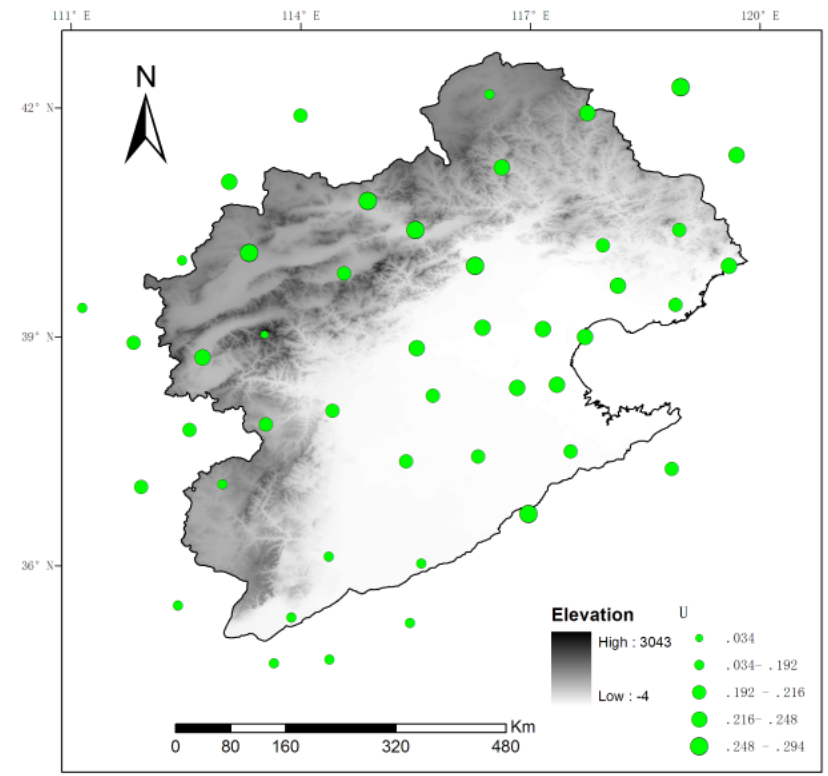

(c)

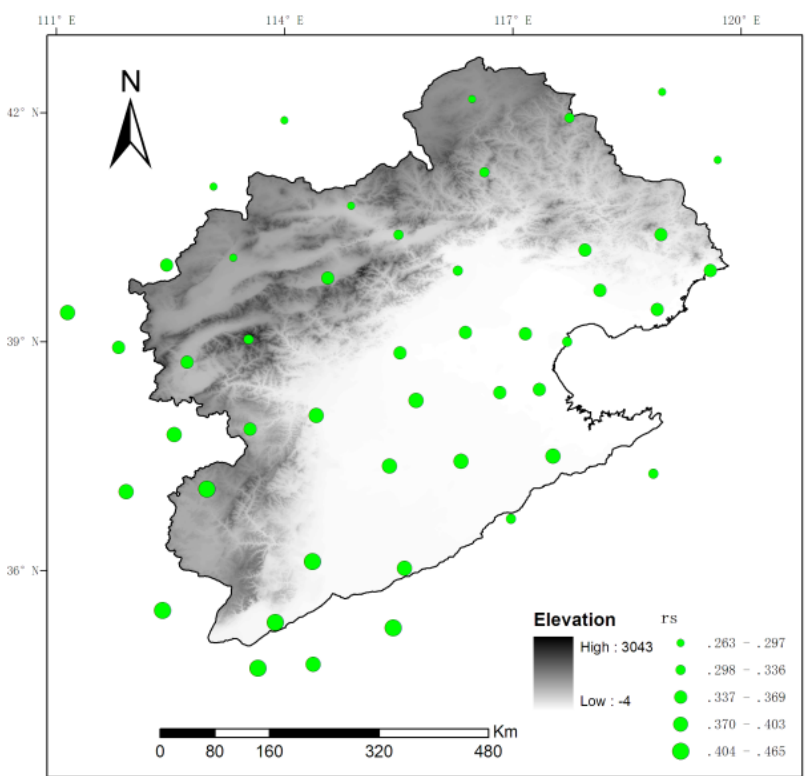

(d)

As for the trend of sensitivity to the climatic variables, the decreasing trends are found in temperature, short wave radiation and relative humidity, while the increasing trend is in wind speed. As variations in sensitivity coefficients to main climatic variables are detected before and after 1990, so the data series of sensitivity coefficients were divided into two groups of 1960-1990 and 1991-2010, respectively, to calculate mean sensitivity coefficients to climatic variables. The obtained results show that before 1990, the sensitivity coefficients to $T_{a}, R h, U$ and $R_{s}$ were $0.500,-0.641,0.205$ and -0.357 , respectively, while after 1990 , they were $0.477,-0.586,0.221$ and 0.349 , respectively.

\subsection{ET with Detrend Climatic Variables}

Figure 7 gives the trend of $\mathrm{ET}_{\mathrm{o}}$ estimated with the detrend data series. The trends of $\mathrm{ET}_{\mathrm{o}}$ with detrend temperature are decreasing, except one station, while the variation pattern of $\mathrm{ET}_{\mathrm{o}}$ with detrend relative humidity is similar to the original $\mathrm{ET}_{\mathrm{o}}$. This shows that there are larger differences between the original $\mathrm{ET}_{\mathrm{o}}$ and the recalculated one with detrend wind speed or detrend shortwave radiation than that with the detrend temperature or relative humidity. This suggests that the decreasing wind speed and shortwave radiation may be the main causes of the decreasing $\mathrm{ET}_{\mathrm{o}}$ in the $\mathrm{HRB}$. As for the decreasing trend of shortwave radiation, previous studies have shown that the decrease in global radiation is the most likely the cause, which is a regional phenomenon. By examining the regional total radiation in eastern China, Zhang [25] concluded that the regional total radiation is decreasing due to the increased air pollution in that area. Another study by Liu [26] also proved that air pollution may result in the decrease of $R_{s}$ in HRB. Therefore, they speculate that aerosols may play a critical role in the decrease of solar radiation in China. 
Figure 7. The annual trend of $\mathrm{ET}_{\mathrm{o}}$ with detrend climatic variables in the HRB. (a) The annual trend of $\mathrm{ET}_{\mathrm{o}}$ in the HRB; (b) The trend of $\mathrm{ET}_{\mathrm{o}}$ with detrend $\mathrm{U}$; (c) The trend of $\mathrm{ET}_{\mathrm{o}}$ with detrend $\mathrm{T}_{\mathrm{a}} ;(\mathbf{d})$ The trend of $\mathrm{ET}_{\mathrm{o}}$ with detrend $\mathrm{R}_{\mathrm{s}} ;(\mathbf{e})$ The trend of $\mathrm{ET}_{\mathrm{o}}$ with detrend $\mathrm{Rh}$.

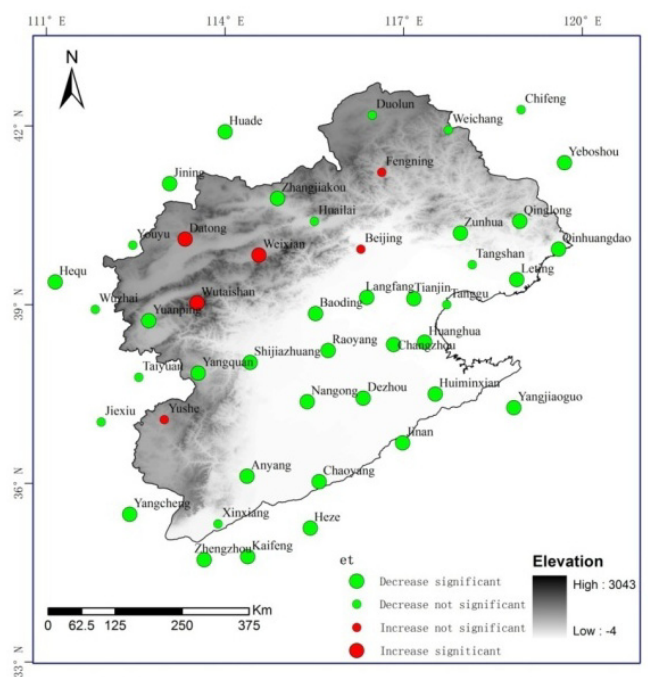

(a)

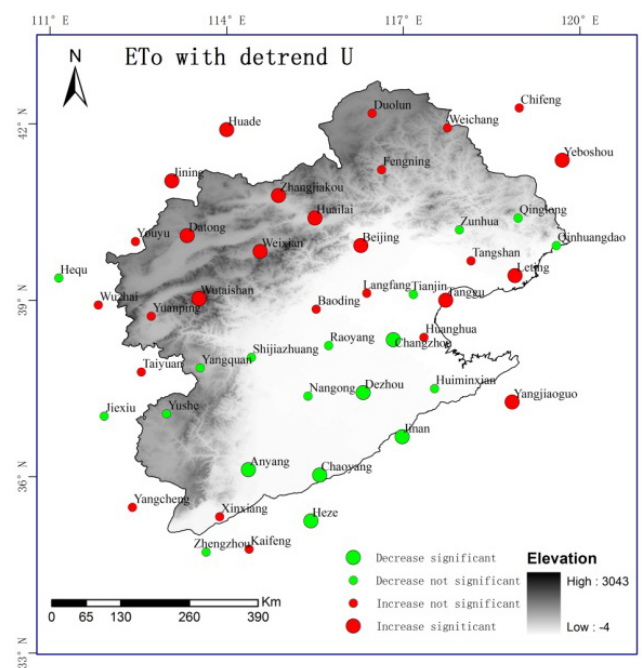

(b)

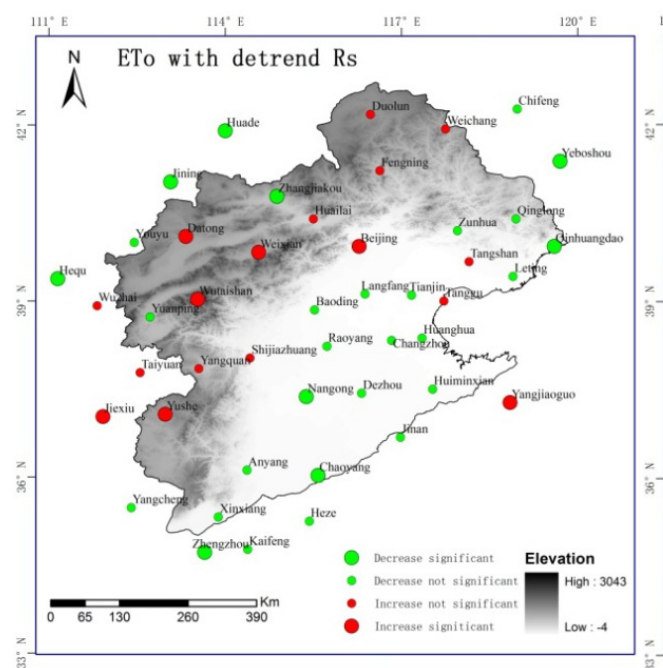

(d)

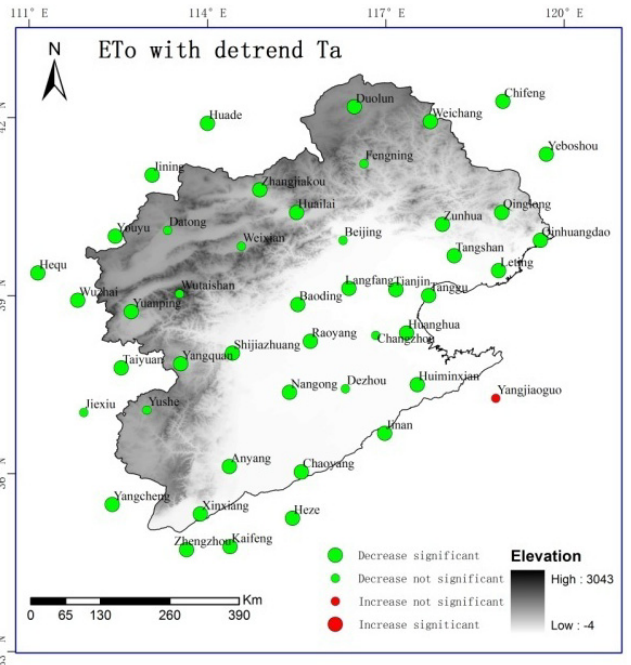

(c)

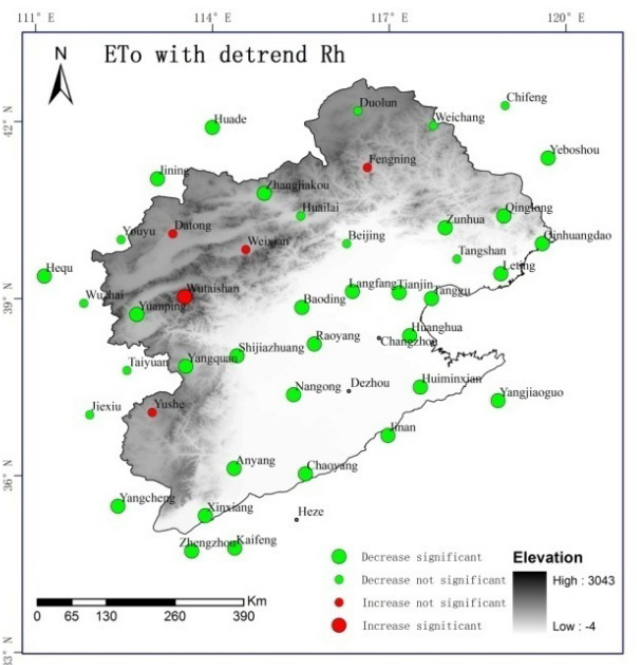

(e) 


\subsection{Relationship between $E T_{o}$ and Human Activity}

The relationship between the variation pattern of $\mathrm{ET}_{\mathrm{o}}$ and human activity refers to how human activity affects climatic variables. In order to detect the relationship between human activity and the variation of climatic variables, the investigated sites were divided into two groups; elevation was taken as the sole criterion of that division. Areas with an elevation higher than $500 \mathrm{~m}$ a.s.1. are usually defined as mountains, while below $500 \mathrm{~m}$ a.s.l. as plains. In general, the population density is higher and human activity is more intense on the plains than in the mountain areas. Figure 8 gives the GDP (Gross Domestic Product) increase from 2000 to 2010 and the distribution of plains in the HRB, respectively. As can be seen, the GDP increased noticeably from 2000 to 2010 on the plains of the HRB. This may suggest that human activity is concentrated on the plains. At the same time, the decrease of $\mathrm{ET}_{\mathrm{o}}$ is more visible on the plains than in the mountains.

Figure 8. The GDP variation and distribution of plain areas in the HRB. (a) GDP variation during 2010 to 2000 in HRB; (b) DEM below 500 m a.s.1. in HRB.

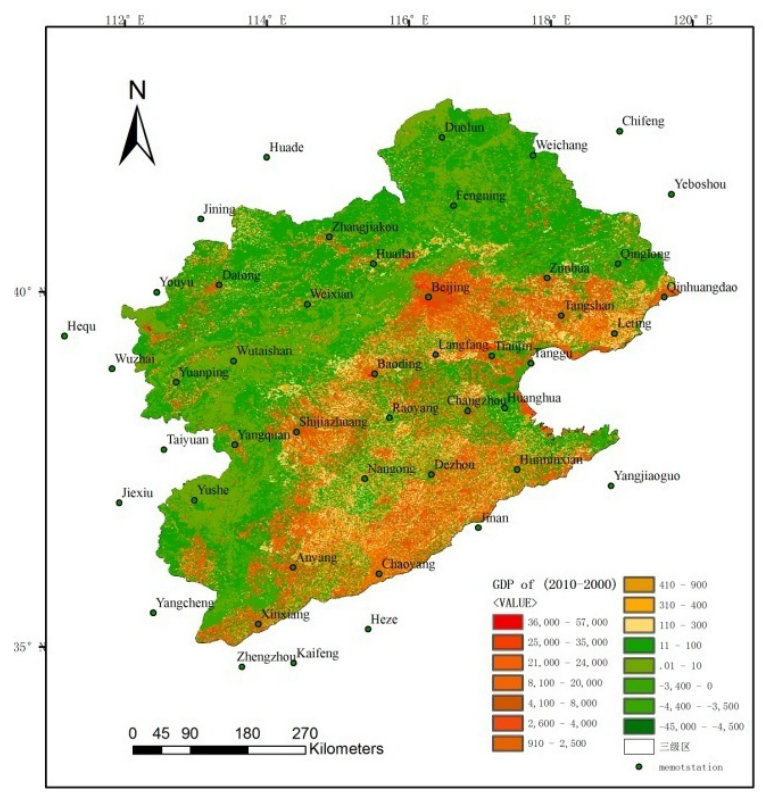

(a)

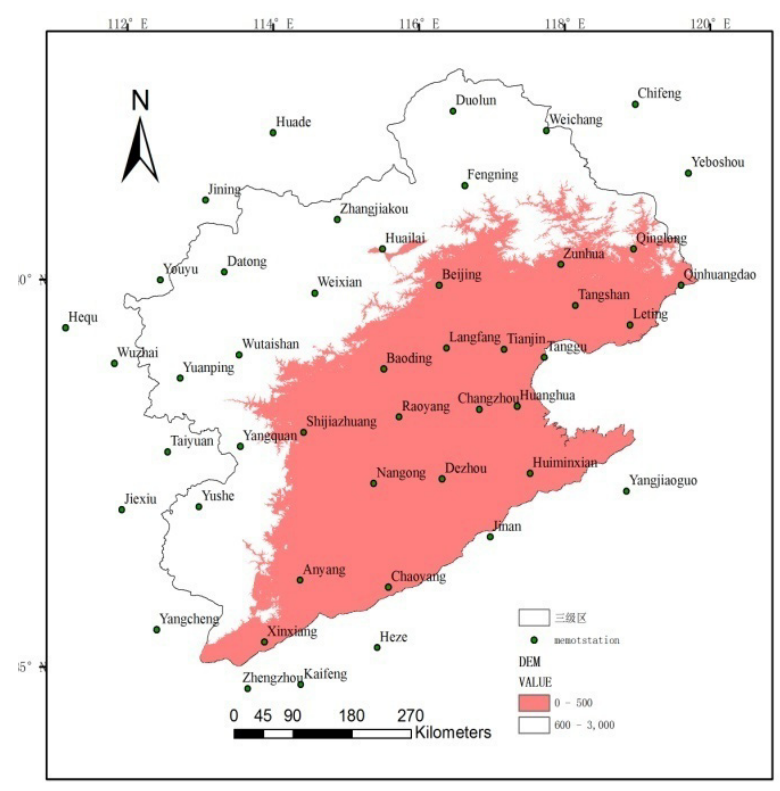

(b)

Table 2 gives the trend of the investigated climatic variables in these two elevation groups. It can be seen that the trend of the shortwave radiation, wind speed and minimum temperature on the plains is more obvious than that in the mountain areas. The detrend results show that the decreasing shortwave radiation and wind speed are the main causes of the decreasing $\mathrm{ET}_{\mathrm{o}}$ on the plains of the HRB. Therefore, we deduce that there is a relationship between the human activity and the decreasing shortwave radiation and wind speed. Liu et al. [26] found that during the period from 1957 to 2008, the solar radiation decreased significantly in the HRB and that the trend was more significant in the densely populated areas than in the sparsely populated ones. The spatial distribution of the aerosol index increase is consistent with the solar radiation decrease. The aerosol increase resulting from human activities was an important reason for the decrease in solar radiation. This phenomenon was also found by some other studies [27-29]. As for the wind speed, Jiang et al. [30] analyzed the change of wind 
speed over China from 1956 to 2004. They found that the effect of urbanization on annual MWS (Mean Wind Speed) is more and more obvious with time, especially in the 1980s. It corresponds with the substantial development of urbanization. At the same time, the declining trend of mean wind speed at the urban stations is more serious than that at the rural ones over the last 50 years. This is coincident with the results given in Table 3.

Table 3. The trend of climatic variables in different elevation groups.

\begin{tabular}{cccccc}
\hline Elevation & $\boldsymbol{R}_{\boldsymbol{s}}$ & $\boldsymbol{T}_{\boldsymbol{m a x}}$ & $\boldsymbol{T}_{\boldsymbol{m i n}}$ & $\boldsymbol{R} \boldsymbol{h}$ & $\boldsymbol{U}$ \\
\hline$>500$ m a.s.1. & -3.689 & 3.698 & 4.727 & -1.157 & -3.773 \\
$<500$ m a.s.1. & -4.601 & 2.170 & 5.198 & -1.348 & -4.739 \\
\hline
\end{tabular}

Furthermore, in order to determine the relationship between $\mathrm{ET}_{\mathrm{o}}$ and human activities, this paper analyzed with the use of the spatial correlation coefficient method the spatial correlation between $\mathrm{ET}_{\mathrm{o}}$, population and meteorological factors, which have a definite effect on $\mathrm{ET}_{\mathrm{o}}$. The results show that the spatial correlation coefficient between population and $\mathrm{ET}_{\mathrm{o}}$ is -0.132 , while the spatial correlation coefficients between population, $R_{s}$ and $R h$ are -0.307 and -0.144 , respectively. Moreover, the spatial correlation coefficients between elevation and $\mathrm{ET}_{\mathrm{o}}$ is 0.667 , while the spatial correlation coefficients between $\mathrm{ET}_{\mathrm{o}}, R_{s}, U$ and $T_{a}$ are $0.749,0.416$ and 0.668 , respectively. This proves that human activity has a certain influence on the spatial variation of $\mathrm{ET}_{\mathrm{o}}$, while natural factors play a decisive role in the spatial variation character of reference evapotranspiration (Table 4).

Table 4. The spatial correlation coefficients between $\mathrm{ET}_{\mathrm{o}}$ and different factors.

\begin{tabular}{cccccc}
\hline $\boldsymbol{R}_{\boldsymbol{s}}$ & $\boldsymbol{U}$ & $\boldsymbol{T}_{\boldsymbol{a}}$ & $\boldsymbol{R} \boldsymbol{h}$ & Population & Elevation \\
\hline 0.749 & 0.416 & 0.668 & -0.267 & -0.132 & 0.667 \\
\hline
\end{tabular}

With increasing altitude and decreasing pressure, the atmosphere is getting thinner and the heat radiation losses become faster. Therefore, the temperature decreases with increasing altitude. At the same time, when the sunlight scattering and reflection decrease, the solar radiation increases. While the proportion of water vapor in the air is relatively large, it is usually concentrated in the lower parts of the atmosphere. Relatively small air moisture content at high altitudes results in low relative humidity there. Friction caused by the uneven Earth surface retards the air flow, so that the wind speed is relatively smaller near the ground. With higher elevation (up to $6000 \mathrm{~m}$ a.s.1.), the wind speed becomes less impacted by the uneven ground.

\section{Conclusions}

In this paper, the spatial and temporal characteristics of annual and seasonal $\mathrm{ET}_{\mathrm{o}}(1960-2010)$ in the Hai River Basin (HRB) were examined, and the possible causes of changes in $\mathrm{ET}_{\mathrm{o}}$ were detected. The following conclusions may be drawn from the study:

(1) Most stations in the HRB have decreasing trends in the annual $\mathrm{ET}_{\mathrm{o}}$ at a confidence level of 95\%. These stations are distributed mainly in the southern and eastern coastal areas of HRB. Three stations (Datong, Wutaishan and Weixian) in the western area of HRB show significant increasing trends in the annual $\mathrm{ET}_{\mathrm{o}}$. As for the seasonal changes, similar characteristics with 
respect to the annual $\mathrm{ET}_{\mathrm{o}}$ were identified only in summer, while during the other three seasons (spring, autumn and winter), the trends were less obvious.

(2) The spatial patterns of the Mann-Kendall trends of the annual meteorological variables show that the maximum and minimum temperatures increase significantly at the 0.05 significance level. However, the increase of the minimum temperature is more apparent than that of the maximum ones all over the basin. Wind speed and shortwave radiation show decreasing trends in the whole basin, and the trends are significant in the eastern and southern parts of the HRB. The sensitivity analysis shows that relativity humidity is the most sensitive variable to $\mathrm{ET}_{0}$, followed by temperature, shortwave radiation and wind speed as the least sensitive to $\mathrm{ET}_{\mathrm{o}}$ in the whole HRB.

(3) Comprehensively considering the sensitivity and variation strength of the meteorological variables, the detrend analysis indicates the decreasing trends in $\mathrm{ET}_{\mathrm{o}}$ dominant in the eastern and southern area of HRB. These may be caused mainly by the behavior of wind speed and shortwave radiation. Meanwhile, the obtained detrend results suggest that the increasing temperature is the main cause of the increasing trend of $\mathrm{ET}_{\mathrm{o}}$ in Datong, Wutaishan and Weixian stations.

(4) The spatial correlation coefficient between population and the trend of $\mathrm{ET}_{\mathrm{o}}$ is -0.132 , and the correlation coefficient between the trend of $\mathrm{ET}_{\mathrm{o}}$ and natural factors is even higher. This suggests that human activity has a certain influence on the spatial variation of $\mathrm{ET}_{\mathrm{o}}$, while natural factors play a decisive role in the spatial variation character of reference evapotranspiration in this area.

\section{Acknowledgments}

The authors are grateful to the National Climate Center of China for providing climatic data. Creative Talents Fund of Guangzhou Institute of Geography, Young Talents Fund of Guangdong Academy of Sciences (rcjj201303) and the Natural Science Foundation of China (No. 51279140) contributed to this research.

\section{Author Contributions}

Ling-ling Zhao is the first person to complete the paper, is responsible for the calculation of the paper, written and modified. Leszek Sobkowiak responsible for checking the language and spelling, Jun Xia and Zongli Li give recommendations in the paper forming process.

\section{Conflicts of Interest}

The authors declare no conflict of interest.

\section{References}

1. Okechukwu, A.; Luc, D.; Souley, Y.K.; le, B.E.; Ibrahim, M.; Abdou, A.; Théo, V.; Bader, J.; Moussa, I.B.; Gautier, E.; et al. Increasing river flows in the Sahel? Water 2010, 2, 170-199.

2. Huntington, T.G. Evidence for intensification of the global water cycle: Review and synthesis. J. Hydrol. 2006, 319, 83-95. 
3. Changchun, X.; Yaning, C.; Yuhui, Y.; Hao, X.M.; Shen, Y.P. Hydrology and water resources variation and its response to regional climate change in Xinjiang. J. Geogr. Sci. 2010, 20, 599-612.

4. Zhao, L.L.; Xia, J.; Xu, C.Y.; Wang, Z.G.; Sobkowiak, L.; Long, C. Evapotranspiration estimated methods in hydrological simulation. J. Geogr. Sci. 2013, 23, 359-369.

5. Feddes, R.A.; Kowalik, P.J.; Zaradny, H. Simulation of Field Water Use and Crop Yield; Centre for Agricultural Publishing and Documentation: Wageningen, Netherlands 1978.

6. Ritchie, J.T. Model for predicting evaporation from a row crop with incomplete cover. Water Resourc. Res. 1972, 8, 1204-1213.

7. Bo, T.; Ling, T.; Shaozhong, K.; Lu, Z. Impacts of climate variability on reference evapotranspiration over 58 years in the Haihe river basin of North China. Agric. Water Manag. 2011, 98, 1660-1670.

8. Jun, X.; Huali, F.; Chesheng, Z.; Cunwen, N. Determination of a reasonable percentage for ecological water-use in the Haihe River Basin, China. Pedosphere 2006, 16, 33-42.

9. Zheng, H.X.; Liu, X.M.; Liu, C.M.; Dai, X.Q.; Zhu, R.R. Assessing contributions to panevaporation trends in Haihe River Basin, China. J. Geophys. Res. Atmos. 2009, 114, doi:10.1029/2009JD012203.

10. Xu, C.Y.; Gong, L.B.; Jiang, T.; Chen, D.L. Decreasing reference evapotranspiration in a warming climatea case of Changjiang (Yangtze) River catchment during 1970-2000. Adv. Atmos. Sci. 2006, 23, 513-520.

11. Liu, B.H.; Xu, M.; Henderson, M.; Gong, W.G. A spatial analysis of pan evaporation trends in China, 1955-2000. J. Geophys. Res. 2004, 109, doi: 10.1029/2004JD004511.

12. Bormann, H. Sensitivity analysis of 18 different potential evapotranspiration models to observed climatic change at German climate stations. Clim. Chang. 2011, 104, 729-753.

13. Coleman, G..; DeCoursey, D.G. Sensitivity and model variance analysis applied to some evaporation and evapotranspiration models. Water Resourc. Res. 1976, 12, 873-879.

14. Gao, G.; Chen, D.L.; Ren, G.Y.; Chen, Y.; Liao, Y.M. Spatial and temporal variations and controlling factors of potential evapotranspiration in China: 1956-2000. J. Geogr. Sci. 2006, 16, $3-12$.

15. Gong, L.B.; Xu, C.Y.; Chen, D.L.; Halldin, S.; Chen, Y.Q. David. Sensitivity of the Penman-Monteith reference evapotranspiration to key climatic variables in the Changjiang (Yangtze River) basin. J. Hydrol. 2006, 329, 620-629.

16. Goyal, R.K. Sensitivity of evapotranspiration to global warming: A case study of arid zone of Rajasthan (India). Agric. Water Manag. 2004, 69, 1-11.

17. Hupet, F.; Vanclooster, M. Effect of the sampling frequency of meteorological variables on the estimation of the reference evapotranspiration. J. Hydrol. 2001, 243, 192-204.

18. McCuen, R.H. A sensitivity and error analysis of procedures used for estimating evaporation1. JAWRA J. Am. Water Resourc. Assoc. 1974, 10, 486-497.

19. Allen, R.G.; Pereira, L.S.; Raes, D.; Smith, M. Crop Evapotranspiration-Guidelines for Computing Crop Water Requirements-FAO Irrigation and Drainage Paper 56; Food and Agriculture Organization: Rome, Italy, 1998; 1-15.

20. Kendall, M.G. Rank Correlation Measures; Charles Griffin: London, UK, 1975; Volume 202.

21. Mann, H.B. Nonparametric tests against trend. Econ. J. Econ. Soc. 1945, 13, 245-259. 
22. Xu, C.Y.; Gong, L.B.; Jiang, T.; Chen, D.L.; Singh, V.P. Analysis of spatial distribution and temporal trend of reference evapotranspiration and pan evaporation in Changjiang (Yangtze River) catchment. J. Hydrol. 2006, 327, 81-93.

23. Chong, S.Z. The Probabilistic Approach in Water Science and Technology; Science Press: Beijing, China, 2010. (In Chinese)

24. Brutsaert, W. Land-surface water vapor and sensible heat flux: Spatial variability, homogeneity, and measurement scales. Water Resourc. Res. 1998, 34, 2433-2442.

25. Zhang, Y.Q.; Liu, C.M.; Tang, Y.H.; Yang, Y.H. Trends in pan evaporation and reference and actual evapotranspiration across the Tibetan Plateau. J. Geophys. Res. Atmos. 2007, 112, doi: 10.1029/2006JD008161.

26. Liu, C.M.; Liu, X.M.; Zheng, H.X.; Zeng, Y. Change of the solar radiation and its causes in the Haihe River Basin and surrounding areas. J. Geogr. Sci. 2010, 20, 569-580.

27. Grimenes, A.A.; Thue-Hansen, V. The reduction of global radiation in south-eastern Norway during the last 50 years. Theor. Appl. Climatol. 2006, 85, 37-40.

28. Qian, Y.; Kaiser, D.P.; Leung, L.R.; Xu, M. More frequent cloud-free sky and less surface solar radiation in China from 1955 to 2000. Geophys. Res. Lett. 2006, 33, doi: 10.1029/2005GL024586.

29. Qian, Y.; Wang, W.G.; Leung, L.R.; Kaiser, D.P. Variability of solar radiation under cloud-free skies in China: The role of aerosols. Geophys. Res. Lett. 2007, 34, doi: 10.1029/2006GL028800.

30. Jiang, Y.; Luo, Y.; Zhao, Z.C.; Tao, S.W. Changes in wind speed over China during 1956-2004. Theor. Appl. Climatol. 2010, 99, 421-430.

(C) 2014 by the authors; licensee MDPI, Basel, Switzerland. This article is an open access article distributed under the terms and conditions of the Creative Commons Attribution license (http://creativecommons.org/licenses/by/3.0/). 